\title{
Hypofunction of Glutamatergic Neurotransmission in the Periaqueductal Gray Contributes to Nerve-Injury-Induced Neuropathic Pain
}

\author{
Yu-Cheng Ho, ${ }^{1}$ Jen-Kun Cheng, ${ }^{5,6,7}$ and Lih-Chu Chiou ${ }^{1,2,3,4}$ \\ ${ }^{1}$ Graduate Institute, ${ }^{2}$ Department of Pharmacology, ${ }^{3}$ Graduate Institute of Brain and Mind Sciences, College of Medicine, ${ }^{4}$ Neurobiology and Cognitive Science \\ Center, National Taiwan University, Taipei 10051, Taiwan; ${ }^{5}$ Department of Anesthesiology, Mackay Memorial Hospital, Taipei 10449, Taiwan, ${ }^{6}$ Mackay Medicine, \\ Nursing and Management College, Taipei 11260, Taiwan, and ${ }^{7}$ Department of Medicine, Mackay Medical College, New Taipei City 25245, Taiwan
}

\begin{abstract}
Neuropathic pain, a chronic pain due to neuronal lesion, remains unaltered even after the injury-induced spinal afferent discharges have declined, suggesting an involvement of supraspinal dysfunction. The midbrain ventrolateral periaqueductal gray (vlPAG) is known to be a crucial supraspinal region for initiating descending pain inhibition, but its role in neuropathic pain remains unclear. Therefore, here we examined neuroplastic changes in the vlPAG of midbrain slices isolated from neuropathic rats induced by L5/L6 spinal nerve ligation (SNL) via electrophysiological and neurochemical approaches. Significant mechanical hypersensitivity was induced in rats $2 \mathrm{~d}$ after SNL and lasted for $>14 \mathrm{~d}$. Compared with the sham-operated group, vlPAG slices from neuropathic rats 3 and 10 days after SNL displayed smaller EPSCs with prolonged latency, less frequent and smaller miniature EPSCs, higher paired-pulse ratio of EPSCs, smaller AMPARmediated EPSCs, smaller AMPA currents, greater NMDAR-mediated EPSCs, greater NMDA currents, lower AMPAR-mediated/NMDARmediated ratios, and upregulation of the NR1 and NR2B subunits, but not the NR2A, GluR1, or GluR2 subunits, of glutamate receptors. There were no significant differences between day 3 and day 10 neuropathic groups. These results suggest that SNL leads to hypoglutamatergic neurotransmission in the vlPAG resulting from both presynaptic and postsynaptic mechanisms. Upregulation of NMDARs might contribute to hypofunction of AMPARs via subcellular redistribution. Long-term hypoglutamatergic function in the vlPAG may lead to persistent reduction of descending pain inhibition, resulting in chronic neuropathic pain.
\end{abstract}

\section{Introduction}

Neuropathic pain is one of leading causes of intractable pain. It is caused by a lesion or dysfunction in the CNS or/and peripheral nervous systems and manifests with persistent hyperalgesia and allodynia (Sandkühler, 2009). Although both central and peripheral mechanisms have been proposed, it remains unclear how neuropathy modulates neural circuits and leads to behavioral hypersensitivity.

In the periphery, ectopic discharges in injured primary afferent nerves was initially proposed to contribute to both the initiation and maintenance of neuropathic pain (Wall and Gutnick, 1974a, 1974b; Chaplan et al., 1994). However, it was later suggested that enhanced discharges in primary afferents are insufficient for maintaining long-term neuropathic pain status without other central mechanisms, because ectopic discharges in injured

Received Dec. 3, 2012; revised March 22, 2013; accepted March 26, 2013.

Author contributions: Y.-C.H. and L.-C.C. designed research; Y.-C.H. performed research; J.-K.C. contributed unpublished reagents/analytic tools; Y.-C.H. and L.-C.C. analyzed data; Y.-C.H., J.-K.C., and L.-C.C. wrote the paper.

This work was supported by the National Science Council, Taipei, Taiwan (Grant\# 101-2325-B002-048 and Grant \#101-2321-B002-081 to L.-C.C.) and the National Health Research Institutes, Miaoli, Taiwan (Grant \#NHRI-EX999506NI and Grant \#NHRI-EX102-10251NI).

The authors declare no competing financial interests.

Correspondence should be addressed to Lih-Chu Chiou, PhD, Professor, Department of Pharmacology, College of Medicine, National Taiwan University, NN. 1, Jen-Ai Rd., Section 1, Taipei 10051, Taiwan. E-mail: Icchiou@ntu.edu.tw.

D01:10.1523/JNEUROSC1.5583-12.2013

Copyright $\odot 2013$ the authors $\quad 0270-6474 / 13 / 337825-12 \$ 15.00 / 0$ nerves occurred $1 \mathrm{~d}$ after nerve lesion and declined gradually over time (Liu et al., 2000).

Increased descending pain facilitation at supraspinal nuclei has been demonstrated in neuropathic pain models. In rats with spinal nerve ligation (SNL), Burgess et al. (2002) found that microinjection of lidocaine, $\mathrm{a} \mathrm{Na}^{+}$channel blocker, into the rostral ventral medulla (RVM) impeded SNL-induced mechanical hypersensitivity and thermal hyperalgesia $6 \mathrm{~d}$, but not $3 \mathrm{~d}$, after SNL, suggesting that descending pain facilitation arising from neuroplastic changes in the RVM is necessary for maintaining, but not initiating, neuropathic pain. Consistently, $7 \mathrm{~d}$ after SNL, the spontaneous firing rate was significantly increased and decreased, respectively, in ON- and OFF-cells in the RVM, the cell types for pronociceptive and antinociceptive responses, respectively (Carlson et al., 2007; Gonçalves et al., 2007). Wei et al. (2008) found that glial-neuronal interactions in the RVM may contribute to the descending pain facilitation after nerve injury. Neuronal loss, possibly OFF-cell, in the RVM after SNL may shift the descending pain inhibition to facilitation (Leong et al., 2011). In the anterior cingulate cortex (ACC), presynaptic glutamate release and postsynaptic GluR1 expression were increased in mice $7 \mathrm{~d}$ after common peroneal nerve injury (Xu et al., 2008).

In addition to the RVM and ACC, the midbrain periaqueductal gray (PAG) plays an important role in pain regulation. It integrates inputs from a variety of higher centers, such as the hypothalamus and amygdala, and sends excitatory outputs to the 
RVM, which sends inhibitory outputs to the spinal dorsal horn, forming the PAGRVM-spinal descending pain inhibitory pathway (Fields et al., 1976; Basbaum and Fields, 1984; Millan, 2002; Heinricher et al., 2009). Downregulation of this descending pain inhibition circuitry may also contribute to the pathogenesis of neuropathic pain. However, except for a few studies reporting changes of glutamate receptor expression in the PAG after nerve injury (Renno, 1998; Hu et al., 2009; Terashima et al., 2012), there has thus far been no study investigating neuroplastic changes and their underlying mecha$\operatorname{nism}(\mathrm{s})$ in the PAG in neuropathic pain models.

In this study, we examined functional and cellular changes in the vlPAG in rats receiving SNL, a model of neuropathic pain, to determine whether alteration of descending pain inhibition from the PAG is involved in the development or/and maintenance of nerveinjury-induced neuropathic pain.

\section{Materials and Methods}

Animals. All experiments adhered to the guidelines approved by the Institutional Animal Care and Use Committee of College of Medicine, National Taiwan University and followed the guidelines of the International Association for the Study of Pain. Efforts were made to minimize the suffering of the animals and the number of animals used in this study.

L5/L6 SNL. The neuropathic pain model induced by right L5/L6 SNL was established in male Sprague Dawley rats (6-8 weeks of age; LASCO) as described previously (Chu et al., 2011). Briefly, in rats anesthetized with isoflurane $(5 \%$ for induction and $2 \%$ for maintenance), the dorsal vertebral column from L4 to S2 was exposed after a midline incision above the lumbar spine. The L5 and L6 spinal nerves were tightly ligated with 4-0 silk suture. The incision was then closed and the rat was allowed to recover and returned to its home cage. Sham-operated rats underwent the same operation and handling as nerve-ligated rats except that they did not receive SNL. Rats that exhibited motor impairment such as paw dragging or dropping or no hypersensitivity to the subsequent innocuous mechanical stimulation were excluded from further experiments.

von Frey filament testing. Mechanical hypersensitivity in rats after SNL was evaluated by the von Frey filament testing as described previously (Cheng et al., 2003). Rats were kept in suspended wire-mesh cages individually and allowed to acclimate for $30 \mathrm{~min}$. The paw-withdrawal threshold to the punctate mechanical stimulation induced by calibrated von Frey filaments with logarithmically incremental stiffness from 0.6 to $26 \mathrm{~g}$ (Stoelting) was measured in the hindpaw ipsilateral or contralateral to the ligation side. Beginning with a $4 \mathrm{~g}$ probe, the filament was applied vertically to the plantar surface of the rat paw for $6 \mathrm{~s}$ while the filament was bent. Brisk withdrawal or paw flinching was considered as a positive response. If a positive response was observed, the filament with the next lower force

B
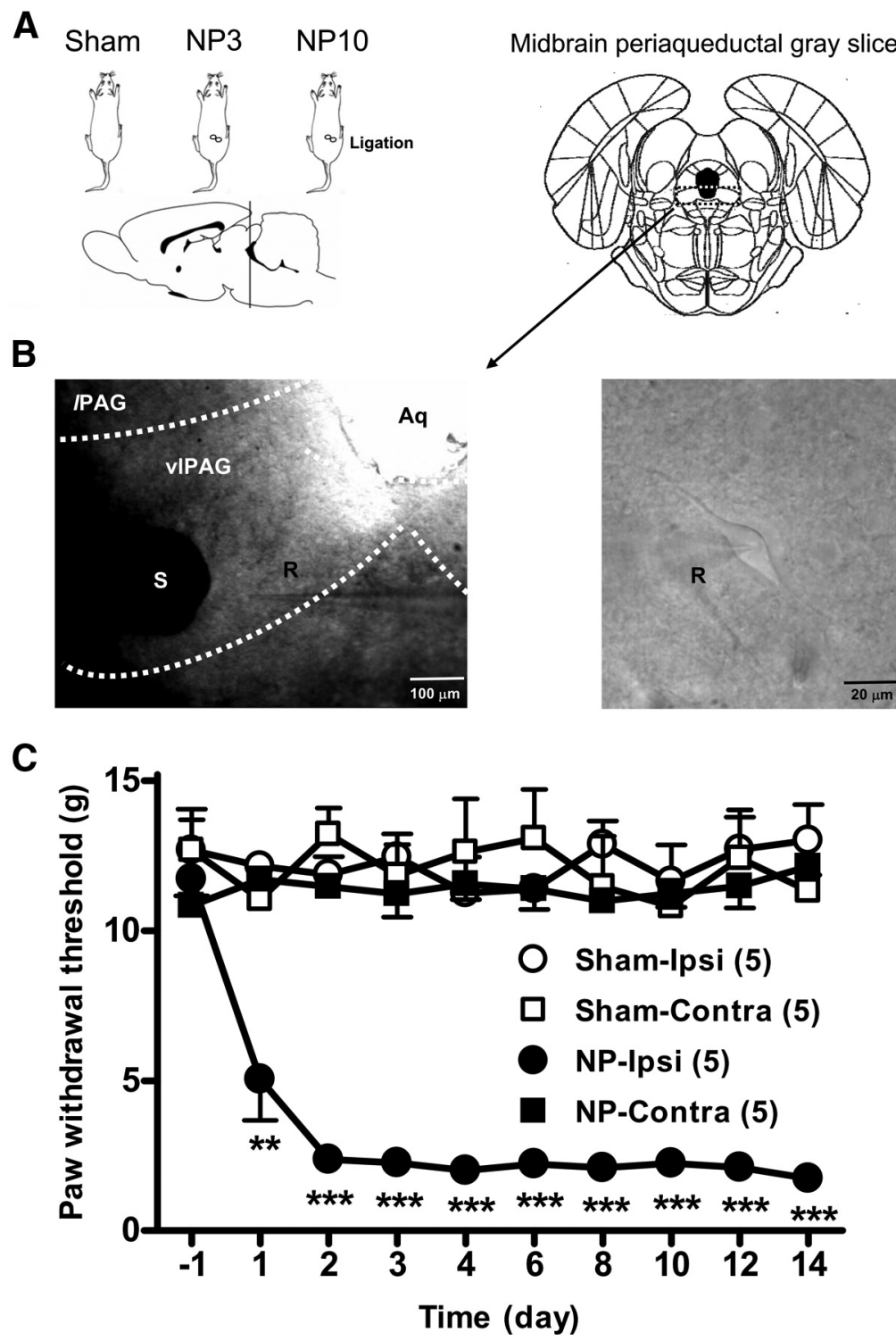

Figure 1. Schema demonstrating the locations of stimulating and recording electrodes in a vIPAG slice dissected from a neuropathic rat induced by L5/L6 SNL. A, Coronal midbrain slice containing the vIPAG dissected from a sham-operated rat and from an NP3 or NP10 rat. $\boldsymbol{B}$, Left: Photomicrograph of a representative coronal midbrain slice where the vIPAG region, the area between two white dotted lines, was selected for conducting electrophysiological recordings. The stimulation electrode $(S)$ was placed 50-200 $\mu \mathrm{m}$ away from the recording electrode. IPAG indicates lateral PAG; Aq, central aqueduct. Right: Higher-power image demonstrating a vIPAG neuron visualized under an IR-DIC microscope, where the whole-cell recording was conducted with a glass recording microelectrode (R). C, Development of mechanical hypersensitivity in rats receiving $\mathrm{L} 5 / \mathrm{L} 6 \mathrm{SNL}$. The ordinate is the paw withdrawal threshold to von Frey filament stimulation, expressed as gram force, and recorded as described in Materials and Methods. Note that mechanical hypersensitivity occurred within $2 \mathrm{~d}$ after SNL and lasted for 2 weeks in the ipsilateral (O), but not the contralateral $(\square)$, hindpaw to the injured side. The sample size $(n)$ is denoted in parentheses for all figures. Two-way ANOVA with repeated measures over time analysis indicated significant differences with a main effect of group $\left(F_{(3,144)}=171.5 ; p<\right.$ $0.001)$ and time $\left(F_{(9,144)}=4.329 ; p<0.001\right)$ and in the interaction of group by time $\left(F_{(27,144)}=3.769 ; p<0.001\right) .{ }^{* *} p<0.01$, $*_{* * *} p<0.001$ compared with the sham group ( $p$ ost hoc Bonferroni's comparisons of the data points denoted).

was applied; otherwise, the next stiffer filament was used. The stimulus force (in $g$ ) producing a $50 \%$ likelihood of paw withdrawal was determined as the withdrawal threshold using the Dixon "up-down" method, as described previously (Chaplan et al., 1994).

Brain slice preparations. Under anesthesia with isoflurane, 6- to 7 -week-old rats were decapitated with a guillotine. Coronal midbrain slices $(300 \mu \mathrm{m})$ containing the PAG (Fig. $1 A$ ) were dissected, as described previously (Chiou and Huang, 1999) with modification, from neuropathic rats that had received SNL for $3 \mathrm{~d}$ (NP3 group) or $10 \mathrm{~d}$ (NP10 group) or from sham-operated rats. After dissection, slices were equilibrated in artificial CSF (aCSF) at room temperature for at least $1 \mathrm{~h}$ before 
recording. The aCSF consisted of the following (in $\mathrm{mm}$ ): $117 \mathrm{NaCl}, 4.5$ $\mathrm{KCl}, 2.5 \mathrm{CaCl}_{2}, 1.2 \mathrm{MgCl}_{2}, 1.2 \mathrm{NaH}_{2} \mathrm{PO}_{4}, 25 \mathrm{NaHCO}_{3}$, and 11.4 dextrose bubbled with $95 \% \mathrm{O}_{2} / 5 \% \mathrm{CO}_{2}, \mathrm{pH} 7.4$. During recordings, one slice was mounted on a submerged recording chamber and continuously perfused with oxygenated aCSF at $2-3 \mathrm{ml} / \mathrm{min}$.

Electrophysiological recordings. Visualized patch-clamp whole-cell recordings were performed in neurons located in the ventrolateral area of PAG slices as described previously (Ho et al., 2011; Liao et al., 2011) with modification. The vlPAG neurons were visualized under a stage-fixed upright IR-DIC microscope (BX51WI; Olympus) equipped with a $40 \times$ water-immersion objective (Fig. $1 B$ ). Recording microelectrodes were filled with a $\mathrm{Cs}^{+}$-based internal solution except the experiments for measuring neuronal excitability, in which a $\mathrm{K}^{+}$-based internal solution was used. The $\mathrm{Cs}^{+}$-based internal solution consisted of the following (in $\mathrm{mm}$ ): $110 \mathrm{Cs}^{+}$gluconate, 5 TEA, 5 QX314, $0.5 \mathrm{CaCl}_{2}, 5 \mathrm{BAPTA}, 10$ HEPES, $5 \mathrm{MgATP}$, and $0.33 \mathrm{GTP}$-Tris (liquid junction potential $=14.6$ $\mathrm{mV}$ ). The $\mathrm{K}^{+}$-based solution contained the following (in $\mathrm{mm}$ ): $125 \mathrm{~K}^{+}$ gluconate, $5 \mathrm{KCl}, 0.5 \mathrm{CaCl}_{2}, 5 \mathrm{BAPTA}, 10 \mathrm{HEPES}, 5 \mathrm{MgATP}$, and 0.33 GTP-Tris, pH 7.3, $280 \mathrm{mOsm} / \mathrm{L}$ (liquid junction potential $=11.4 \mathrm{mV}$ ). The electrode resistance was $4-6 \mathrm{M} \Omega$.

Neuronal excitability. The membrane excitability of the recorded neuron was measured in the current-clamp mode by the number of action potentials elicited by intracellular injection of 20,40 , and $60 \mathrm{nA}$ depolarizing currents for $200 \mathrm{~ms}$.

EPSCs. In vlPAG slices, we have proven that glutamatergic EPSCs can be evoked by local stimulation and that fast EPSCs, which are mediated by AMPARs, can be recorded at $-70 \mathrm{mV}$ after blocking GABAergic transmis-

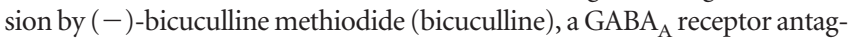
onist (Chiou and Chou, 2000). Therefore, EPSCs were recorded at $-70 \mathrm{mV}$ in the presence of $10 \mu \mathrm{M}$ bicuculline. They were evoked at $0.05 \mathrm{~Hz}$ by square wave pulses $(10-50 \mathrm{~V}, 150 \mu \mathrm{s})$ from a stimulator (S88; Grass Telefactor) through a bipolar concentric electrode (Frederick Haer) placed 50-200 $\mu \mathrm{m}$ away from the recording electrode (Fig. $1 B$ ). In each neuron, the stimulation voltage was adjusted to elicit an EPSC with an amplitude 70$80 \%$ of the maximal amplitude, except the experiment for establishing the input-output (I-O) relationship (see below).

Miniature EPSCs. Miniature EPSCs (mEPSCs) were recorded in the presence of bicuculline and tetrodotoxin (TTX; $1 \mu \mathrm{M}$ ), a Na ${ }^{+}$channel blocker that inhibits action-potential-driven spontaneous neurotransmitter release. Mini Analysis 6.0 software (Synaptosoft) was used to analyze the amplitude and frequency of mEPSCs. The KolmogorovSmirnov test was used to compare the cumulative probability of the frequency and amplitude of mEPSCs.

I-O relationship. The I-O relationship of glutamatergic transmission in vlPAG slices was constructed by the stimulation intensity (input) and the amplitude of EPSCs (output). In each neuron, 12 EPSCs were evoked by $10,20,30,40$, and $50 \mathrm{~V}$ and averaged. When the latency of the EPSC was measured, it was defined as the time difference between the stimulation artifact and the takeoff of the EPSC.

Paired-pulse ratio of EPSCs. When the paired-pulse ratio (PPR) of EPSCs was examined, paired pulses with interstimulus intervals of 25, $50,75,100$, and $200 \mathrm{~ms}$ were given every $20 \mathrm{~s}$ as described previously (Xu et al., 2008). Every three pairs of EPSCs evoked at each interval were averaged and the PPR was defined as the ratio of the averaged amplitude of the second EPSC (EPSC2) to that of the first EPSC (EPSC1).

Current-voltage curves of EPSC $C_{A M P A}$ and $E P S C_{N M D A}$. AMPA-receptormediated EPSCs (EPSC ${ }_{\mathrm{AMPA}} \mathrm{s}$ ) were recorded in the presence of $50 \mu \mathrm{M}$ 2-amino-5-phosphonopentanoic acid (APV), an NMDAR blocker, and $10 \mu \mathrm{M}$ bicuculline. NMDAR-mediated EPSCs (EPSC $\left.\mathrm{NMDA}_{\mathrm{NM}} \mathrm{s}\right)$ were recorded in the presence of $20 \mu \mathrm{M}$ 6-cyano-7-nitroquinoxaline-2,3-dione (CNQX), an AMPAR blocker, and $10 \mu \mathrm{M}$ bicuculline. $\mathrm{EPSC}_{\mathrm{AMPA}} \mathrm{s}$ and EPSC $_{\mathrm{NMDA}} \mathrm{S}$ were recorded at $-60,-40,-20,0,+20$, and $+40 \mathrm{~V}$ and nine EPSCs at each voltage were averaged to establish their currentvoltage $(I-V)$ curves.

$E P S C_{A M P A} / E P S C_{N M D A}$ ratio. To compare the postsynaptic response of glutamatergic transmission among different groups, the ratio of $\mathrm{EPSC}_{\mathrm{AMPA}} / \mathrm{EPSC}_{\mathrm{NMDA}}$ recorded in the same neuron was examined as described previously (Ungless et al., 2001). In the presence of bicuculline
$(10 \mu \mathrm{M})$, the EPSCs in a neuron were first recorded at $-70 \mathrm{mV}$ where NMDARs are blocked by the $\mathrm{Mg}^{2+}$ in the aCSF to assess the $\mathrm{EPSC}_{\mathrm{AMPA}} \mathrm{s}$; then, in the same neuron, $20 \mu \mathrm{M}$ CNQX was also added and EPSCs were recorded at $+40 \mathrm{mV}$ to assess the $\mathrm{EPSC}_{\mathrm{NMDA}} \mathrm{s}$. In every neuron, nine EPSC $_{\mathrm{AMPA}} \mathrm{s}$ and $\mathrm{EPSC}_{\mathrm{NMDA}} \mathrm{s}$ were averaged and the ratio of $\mathrm{EPSC}_{\mathrm{AMPA}} /$ EPSC $_{\mathrm{NMDA}}$ was calculated.

AMPA and NMDA currents. AMPA- and NMDA-induced currents were elicited by puff application of AMPA and NMDA, respectively, to the surface of the recorded vlPAG neuron and were recorded at $-70 \mathrm{mV}$ and $+40 \mathrm{mV}$, respectively, as described previously (Lee et al., 2008). Briefly, the AMPA $(1 \mu \mathrm{M})$ or NMDA $(10 \mu \mathrm{M})$ solution was loaded into a glass pipette ( $2 \mu \mathrm{m}$ tip diameter) and ejected by a Picospritzer (General Valve). The solution was ejected onto the recorded neuron for $5 \mathrm{~s}$ by applying an 8 psi pressure via the glass pipette, which was $10-20 \mu \mathrm{m}$ above the recorded neuron. In the presence of TTX $(1 \mu \mathrm{M})$ and bicuculline $(10 \mu \mathrm{M})$, AMPA and NMDA currents were recorded with APV (50 $\mu \mathrm{M})$ and CNQX $(20 \mu \mathrm{M})$, respectively.

Western blotting. Glutamate receptor subunits in the rat vlPAG were measured as described previously (Bagley et al., 2005) with modifications. Briefly, the midbrain block containing the PAG was isolated from three groups of rats and sliced into 300- $\mu$ m-thick sections. The vlPAG region was microdissected bilaterally from each section. The solubilization of membrane receptors was conducted as described previously (Sheng et al., 2002). Microdissected vlPAG samples from each rat were collected, lysed in a nondenaturing-detergent-containing tissue protein extraction reagent (T-PER, catalog \#78510; Pierce Biotechnology), sonicated, and centrifuged at $15,000 \times g$ at $4^{\circ} \mathrm{C}$ for $30 \mathrm{~min}$. The supernatant was then assayed for the total protein amount using a protein assay kit (Bio-Rad). Each brain tissue sample taken from a rat was separated in an 8\% SDS-PAGE gel for GluR1, GluR2, and NMDAR1 subunit analysis or in a 6\% gel for NMDAR2A and NMDAR2B subunit analysis. After transferring onto nitrocellulose membranes, blots were blocked with a buffer solution containing 5\% milk and $0.1 \%$ Tween 20 in PBS at pH 7.2 for $1 \mathrm{~h}$. The blot was incubated with the primary antibody recognizing the respective subunit of glutamate receptors overnight at $4^{\circ} \mathrm{C}$, including GluR1 (1:10,000, catalog \#3861-1, lot YH122305C; Epitomics), GluR2 (1:1000, catalog \#3520-1, lot YH081712D; Epitomics), NR1 (1:1000, catalog \#2824-1, lot YG060310C; Epitomics), NR2A (1:1000, catalog \#4205S, lot 1; Cell Signaling Technology), or NR2B (1:1000, catalog \#4212S, lot 1; Cell Signaling Technology). All antibodies are rabbit monoclonal antibodies except the NR2A antibody, which is polyclonal. The specificity of the antibodies purchased was not reconfirmed in this study because it was already confirmed by Cell Signaling Technology with preabsorption control experiments. The membrane was then washed with Tris-buffered saline and incubated for $1 \mathrm{~h}$ with HRPconjugated secondary antibody. Immunoreactivity was detected using enhanced chemiluminescence (PerkinElmer Life Sciences). The loading and blotting of equal amounts of protein were verified by reprobing the membrane with anti- $\beta$-actin antiserum (1:1000, catalog \#MAB1501, lot LV1435643; Millipore). Immunoblots were quantified using Image Quant 5.2 software (Molecular Dynamics).

Statistical analysis. Data are expressed as the mean \pm SEM; $n$ indicates the number of the animals sampled in behavioral or Western blotting experiments or the number of neurons recorded in electrophysiological experiments. From each rat, 4-5 slices were dissected and 1-2 neurons were sampled (1 neuron from 1 slice). Because the neuropathic pain (NP) groups had fewer healthy neurons, successful recordings were usually obtained after having examined $4-5$ slices from a neuropathic rat but only $1-2$ slices from a sham-control rat. Statistical comparison was performed by one-way ANOVA (using Dunnett's correction for post hoc analysis), two-way ANOVA (using Bonferroni correction for post hoc analysis), or unpaired Student's $t$ test where appropriate. Differences were considered significant if $p<0.05$.

Chemicals. (-)-Bicuculline methiodide, TTX, CNQX, AMPA, NMDA, and APV were purchased from Tocris Bioscience. All drugs were prepared as a 1000 -fold concentrated stock solution and diluted to the final concentration with aCSF. CNQX was dissolved in dimethylsulfoxide. The final concentration of dimethylsulfoxide was $<0.1 \%$, which had no effect per se. Other drugs were dissolved in deionized water. 

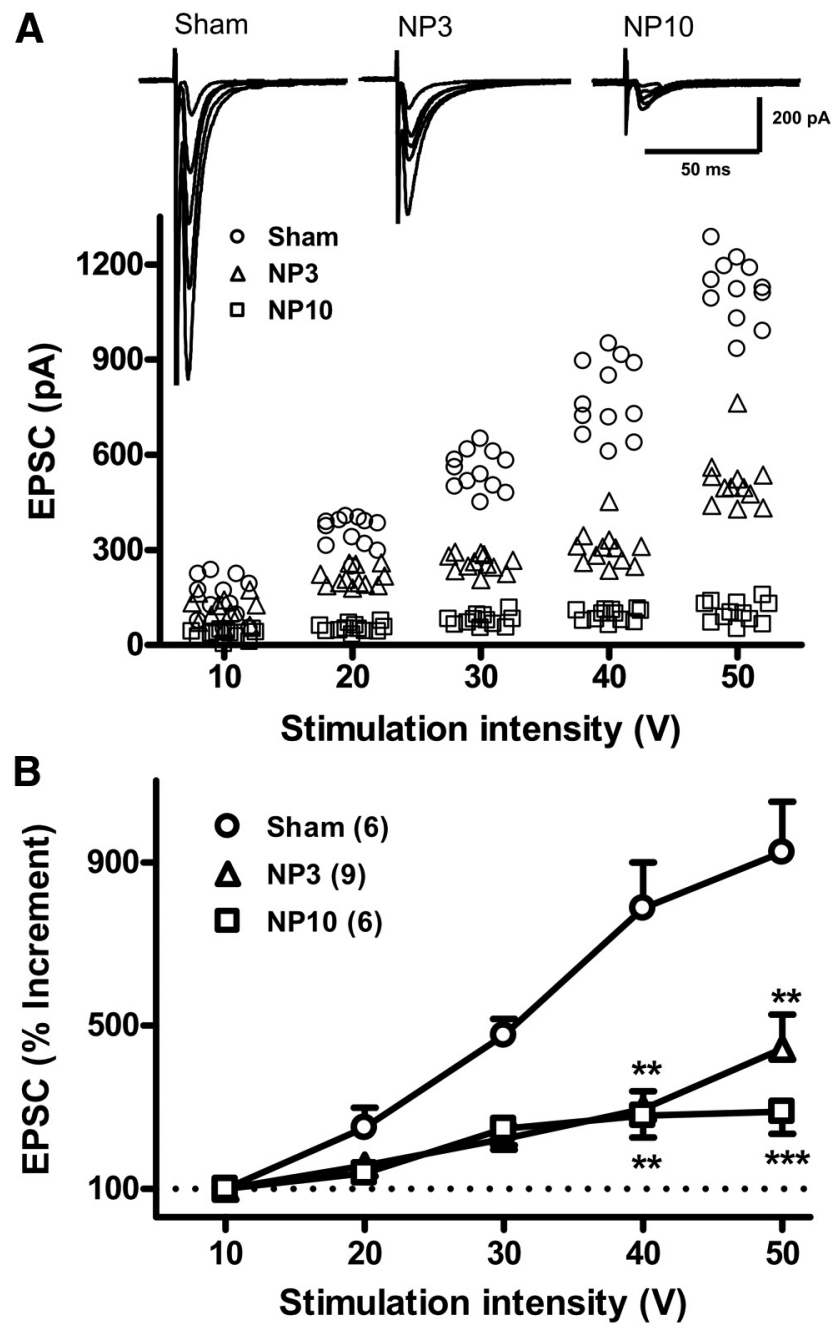

Figure 2. SNL led to low efficiency of I-0 transfer of glutamatergic transmission in vIPAG slices. $A, I-0$ relationship of glutamatergic transmission established by the stimulation intensity (synaptic input) and the amplitude of EPSC (output) in slices isolated from sham-operated (Sham), NP3, and NP10 rats. Representative EPSCs evoked by 10, 20, 30, 40, and $50 \mathrm{~V}$, respectively, were recorded in a vIPAG neuron of a slice isolated from the sham, NP3, or NP10 group. $\boldsymbol{B}$, Averaged I- 0 curves of glutamatergic transmission in sham, NP3 and NP10 groups. The I- 0 curve was constructed by the percentage increment of the EPSC evoked at each stimulation intensity in each neuron, taking the EPSC evoked by $10 \mathrm{~V}$ as $100 \%$. Note that the slope of the $\mathrm{I}-0$ curve in NP3 $(\triangle)$ and NP10 $(\square)$ groups was significantly smaller than that in the sham group $(\bigcirc)$. Two-way ANOVA with repeated measures over intensity analysis indicated significant differences with a main effect of group $\left(F_{(2,72)}=20.43 ; p<0.001\right)$ and intensity $\left(F_{(4,72)}=42.93\right.$; $p<0.001)$ and in the interaction of group by intensity $\left(F_{(8,72)}=7.986 ; p<0.001\right)$. ${ }^{* *} p<$ $0.01,{ }^{* * *} p<0.001$ compared with the sham group ( post hoc Bonferroni's comparisons of the data points denoted). $n$ in the parentheses are the number of tested neurons in all the figures with electrophysiological experiments. Usually, 1 neuron was recorded from 1 slice and 1-2 slices were sampled from a sham-operated rat, whereas 1-2 neurons were successfully recorded from $4-5$ slices isolated from an NP rat.

\section{Results}

Establishment of mechanical hypersensitivity in SNL rats After SNL, the hindpaw withdrawal threshold to mechanical stimulation induced by the von Frey filament in rats was significantly decreased in the ipsilateral, but not contralateral, side compared with the sham-operated group (Fig. 1C). This mechanical hypersensitivity reached steady state $2 \mathrm{~d}$ after SNL and lasted for at least $14 \mathrm{~d}$ (Fig. 1C). The paw withdraw threshold on day $3(2.26 \pm 0.23 \mathrm{~g}, n=5)$ after SNL was not significantly different from that on day $10(2.25 \pm 0.34 \mathrm{~g}, n=5)$ or that on day
A

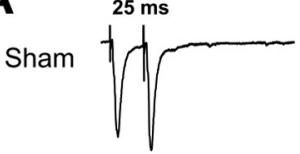<smiles>CCC1CCCCC1CC</smiles>

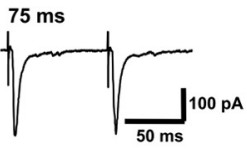

NP3
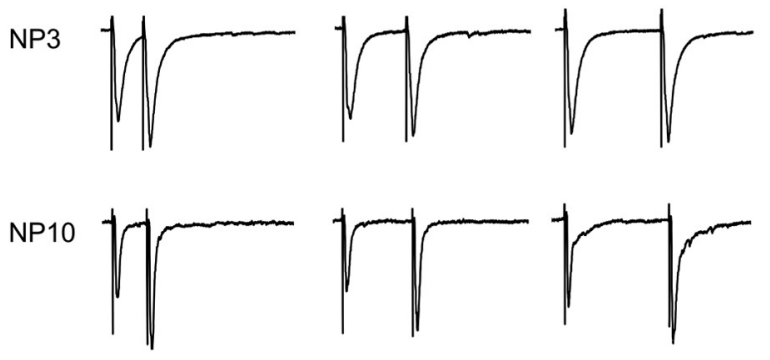

B

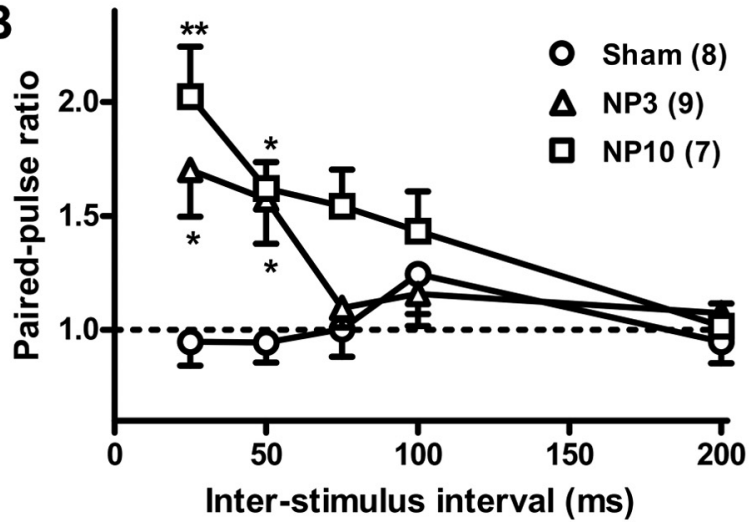

Figure 3. SNL led to reduced presynaptic glutamate release, revealed by increased PPR of EPSCS, in vIPAG slices. Paired EPSCs were evoked by paired pulses with intervals of $25,50,75$, 100 , and $200 \mathrm{~ms}$. PPR was measured by the amplitude ratio of the second EPSC to the first one. $A$, Representative paired EPSCs evoked by 25,50 , and 75 ms-separated paired pulses in sham, NP3, and NP10 groups. $B$, PPR evoked at various intervals in the sham $(O), N P 3(\triangle)$, and NP10 $(\square)$ groups. Two-way ANOVA with repeated measures over interstimulus interval analysis indicated significant differences with a main effect of group $\left(F_{(2,84)}=11.25 ; p<0.001\right)$ and interstimulus interval $\left(F_{(4,84)}=6.054 ; p<0.001\right)$ and in the interaction of group by interstimulus interval $\left(F_{(8,84)}=2.799 ; p<0.01\right)$. One-way ANOVA analysis indicated significant differences at 25 and $50 \mathrm{~ms}$ intervals in the NP groups compared with the sham group ( $25 \mathrm{~ms}$ interval, $F_{(2,21)}=8.682$, one-way ANOVA, $p<0.01$, post hoc Dunnett's test; 50 ms interval, $F_{(2,21)}=6.438$, one-way ANOVA, $p<0.01$, post hoc Dunnett's test $)^{*} p<0.05$, ${ }^{* *} p<0.01$ compared with the sham group.

$14(1.74 \pm 0.13 \mathrm{~g}, n=5)$, suggesting that sustained ipsilateral neuropathic pain is induced from day 3 after SNL in rats. This time course is consistent with findings in which neuroplastic changes in the RVM were studied in the same model (Burgess et al., 2002). Therefore, in the subsequent electrophysiological studies, PAG slices were isolated from rats 3 and $10 \mathrm{~d}$ after SNL defined as the NP3 and NP10 groups, respectively.

\section{SNL leads to low I-O transfer efficiency in vlPAG} glutamatergic transmission Compared with the sham group, it was more difficult to obtain successful whole-cell recordings and elicit EPSCs in the vlPAG slices isolated from neuropathic rats. Because fewer healthy neurons were found in the brain slices dissected from NP groups, the chances of obtaining successful whole-cell configuration in the NP groups were less than those in the sham group. The following data were obtained in neurons with successfully whole-cell recordings. The I-O relationships of the glutamatergic transmission established by the magnitude of EPSC versus the stimulation intensity in vlPAG slices isolated from sham, NP3, and NP10 
A

\section{Sham}

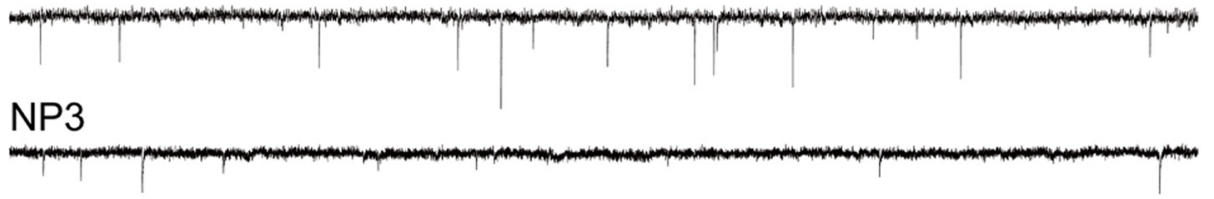

NP10

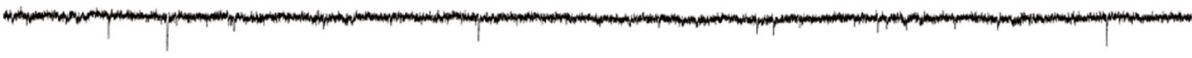

\section{Sham + CNQX}

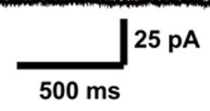

B

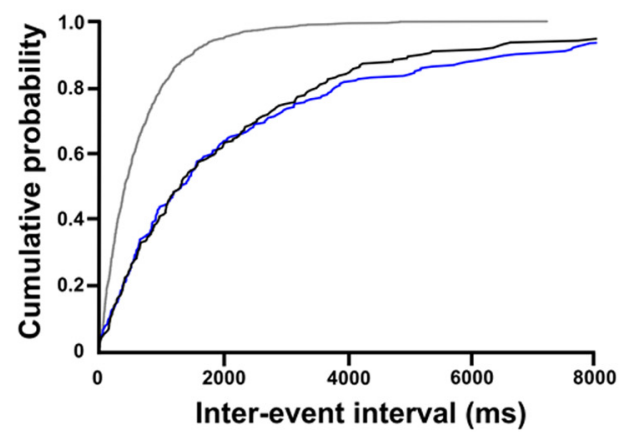

D

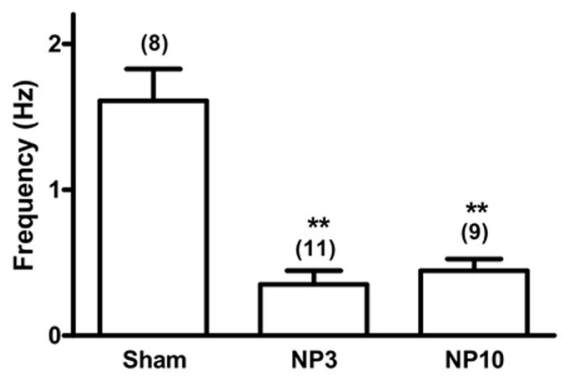

C

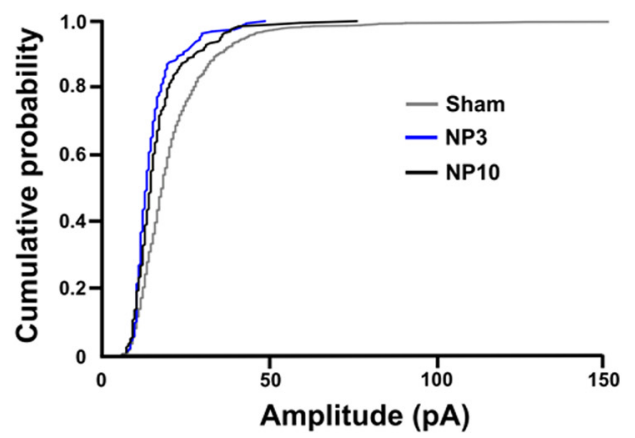

E

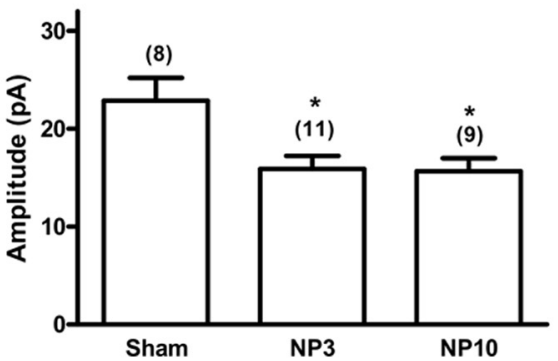

Figure 4. SNL led to less frequent and smaller miniature EPSCs in vIPAG slices. mEPSCs were recorded at $-70 \mathrm{mV}$ in the presence of $1 \mu \mathrm{m}$ TTX and $10 \mu \mathrm{m}$ bicuculline. $\boldsymbol{A}$, Representative trace of mEPSCs recorded in a vIPAG slice isolated from a sham, NP3, or NP10 rat or a rat from the sham group treated with $20 \mu M$ CNQX. $B, C$, Cumulative probability histograms of the interevent interval $(\boldsymbol{B})$ or amplitude $(\boldsymbol{C})$ of mEPSCs in the three groups. Note that the interevent interval of mEPSCs $(\boldsymbol{B})$ was significantly longer and the amplitude $(\boldsymbol{C})$ was smaller in NP3 and NP10 groups than in the sham group ( $p<0.01$, Kolmogorov-Smirnov test). $\boldsymbol{D}, \boldsymbol{E}$, Bar charts of averaged frequency, $\left(F_{(2,25)}=26.23\right.$, one-way ANOVA, $\left.p<0.001 ; \boldsymbol{D}\right)$, and amplitude, $\left(F_{(2,25)}=5.647\right.$, one-way ANOVA, $p<$ $0.01 ; \boldsymbol{E})$ of mEPSCs in the sham, NP3, and NP10 groups. ${ }^{*} p<0.05,{ }^{* *} p<0.01$ compared with the sham group (post hoc Dunnett's test).

groups were compared. The amplitude of EPSCs increased gradually with increasing stimulation intensity from 10 to $50 \mathrm{~V}$ in all the three groups (Fig. 2); however, compared with the sham group, smaller EPSCs were evoked with the same stimulation intensity in both the NP3 and NP10 groups (Fig. 2). Increasing stimulation intensity induced limited increases in the amplitude of EPSCs in both the NP3 and NP10 groups. NP groups showed a significant decrease in stimulus-induced responses. This led to a flat slope in the I-O curve in either NP3 or NP10 group, which was markedly different from the steep slope in the sham group (Fig. 2B). The percentage increment of EPSCs by increasing stimulation intensity from 10 to $50 \mathrm{~V}$ in the sham group ( $924 \pm 124 \%$, $n=6$ ) was significantly higher than that in the NP3 (444 $\pm 84 \%$, $n=9)$ or NP10 (289 $\pm 55 \%, n=6)$ groups, whereas the increments between the NP3 and NP10 groups were not significantly different ( $p=0.19$; Fig. $2 B$ ). These results suggest that the I-O transfer efficiency of excitatory synaptic transmission is impaired in the vlPAG of rats after SNL.

\section{SNL leads to hypofunction of glutamatergic} neurotransmission in the vlPAG via both presynaptic and postsynaptic mechanisms

Increased PPR in SNL groups

To determine whether the impairment of the glutamatergic I-O relationship in the vlPAG could be attributed to presynaptic or postsynaptic changes after SNL, we compared the PPR of EPSCs, 
which depends on the presynaptic release machinery (Zucker and Regehr, 2002). In the sham group, no paired-pulse facilitation of EPSCs was elicited when the interpulse interval was $25 \mathrm{~ms}$ ( $p=0.63$, one sample $t$ test $)$ and $50 \mathrm{~ms}(p=0.54$, one sample $t$ test). However, significant paired-pulse facilitation was observed at 25 and $50 \mathrm{~ms}$ intervals in both the NP3 and NP10 groups (Fig. 3). PPRs in the NP3 and NP 10 groups were significantly greater than those in the sham group (Fig. $3 B)$. There was no significant difference in the PPRs at $25 \mathrm{~ms}(p=0.31)$ and $50 \mathrm{~ms}$ $(p=0.84)$ intervals between the NP3 and NP10 groups, suggesting that the presynaptic glutamate release in the vlPAG of neuropathic rats is impaired.

Lower mEPSC frequency and amplitude in SNL groups

To further investigate the presynaptic and postsynaptic contributions in SNLinduced hypofunction of vlPAG glutamatergic transmission, we compared mEPSCs in slices from the three groups. The mEPSCs recorded in the vlPAG slices isolated from the sham group were blocked by CNQX, suggesting that they are AMPAR mediated (Fig. $4 A$ ). In both the NP3 and NP10 groups, mEPSCs were smaller and less frequent than in the sham group (Fig. 4A). The mean frequency of mEPSCs in the NP3 and NP10 groups was only $21.9 \pm 6 \%$ and $27.6 \pm 5 \%$ of the sham group, respectively (Fig. $4 D$ ) and their mean amplitude was $69.6 \pm 6 \%$ and $68.5 \pm 6 \%$ of the sham group, respectively (Fig. $4 E$ ). The finding of markedly lower mEPSC frequency in the NP groups, although it might be confounded by indistinguishable small mEPSCs, suggests a presynaptic contribution in SNL-induced hypoglutamatergic function in the vlPAG.

The smaller mEPSCs in the NP groups could have been caused by a timeassociated degradation of the slices: because there were fewer healthy neurons in the NP groups, more slices had to be examined. However, this possibility can be excluded by the result that the NP3 and NP10 groups still had significantly smaller mEPSCs than the sham group when only the data from the first recorded slices were compared. The average mEPSC amplitude in the first recorded slices in the sham, NP3, and NP10 groups, respectively, was $22.94 \pm 3.62 \mathrm{pA}(n=5), 14.92 \pm 1.55 \mathrm{pA}(n=$ $8)$, and $15.71 \pm 1.33 \mathrm{pA}(n=7)\left(F_{(2,17)}=5.096\right.$, one-way ANOVA, $p<0.05$, post hoc Dunnett's test comparisons).

\section{Reduced AMPA currents and enhanced NMDA currents in the} NP groups

The finding of smaller AMPAR-mediated mEPSCs in the NP groups (Fig. $4 A$ ) suggests an impairment in the function or/and number of postsynaptic AMPARs or a decrease in the presynaptic vesicle size in the vIPAG after SNL. Therefore, in these three
B

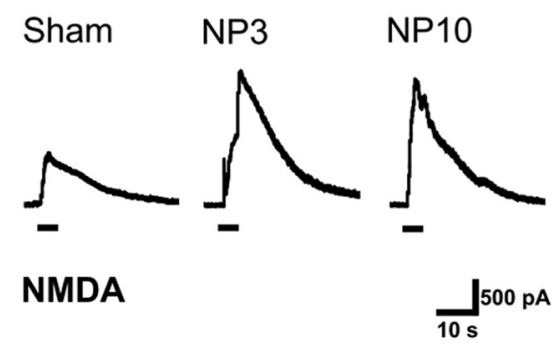

D

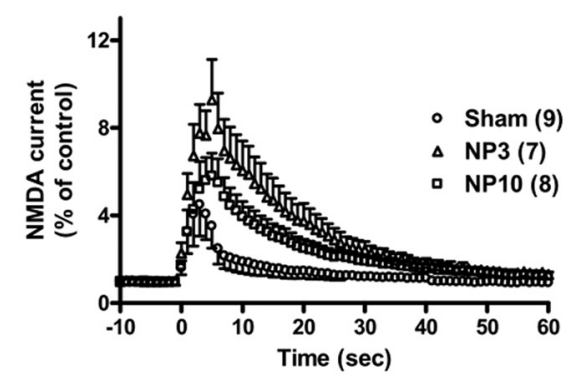

$\mathbf{F}$

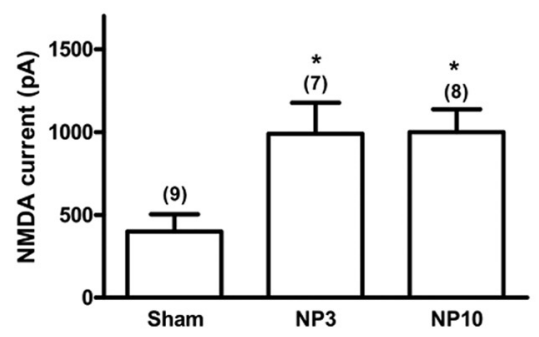

Figure 5. SNL resulted in smaller AMPA currents and greater NMDA currents in vIPAG slices. AMPA and NMDA currents were 年

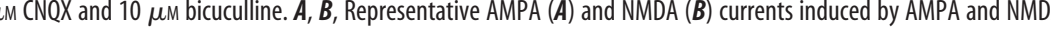
and NMDA $(\boldsymbol{D})$ currents recorded in the sham $(\bigcirc), \mathrm{NP3}(\triangle)$, and NP10 $(\square)$ groups. Normalized AMPA $(\boldsymbol{C})$ and NMDA (D) currents baseline current at $-70 \mathrm{mV}$ and $+40 \mathrm{mV}$, respectively. $\boldsymbol{E}, \boldsymbol{F}$, Averaged AMPA $(\boldsymbol{E})$ and NMDA $(\boldsymbol{F})$ currents recorded from vIPAG slices taken from sham, NP3, and NP10 rats. Note that the AMPA current was significantly smaller $\left(F_{(2,23)}=7.596\right.$, one-way ANOVA, $p<$ $0.01 ; \boldsymbol{E})$ but the NMDA current was larger $\left(F_{(2,21)}=6.296\right.$, one-way ANOVA, $\left.p<0.01 ; \boldsymbol{F}\right)$ in the NP groups compared with the sham group. ${ }^{*} p<0.05,{ }^{* *} p<0.01$ compared with the sham group ( post hoc Dunnett's test).

groups, we further compared AMPAR-mediated currents induced by exogenous AMPA and the current mediated by NMDARs, which are also important postsynaptic glutamatergic receptors in the vlPAG (Chiou and Chou, 2000).

Puff application of AMPA $(1 \mu \mathrm{M})$ for $5 \mathrm{~s}$ onto the vlPAG neurons held at $-70 \mathrm{mV}$ induced an inward AMPA current (Fig. $5 A$ ). These AMPA-induced currents in the sham group were significantly larger than those in both the NP3 and NP10 groups, but were not significantly different between the NP3 and NP10 groups (Fig. $5 A, C, E$ ).

Puff application of NMDA $(10 \mu \mathrm{M})$ for $5 \mathrm{~s}$ onto the vlPAG neurons held at $+40 \mathrm{mV}$ induced an outward current (Fig. 5B). In contrast to AMPA currents, NMDA-induced currents in the NP groups were significantly larger than those in the sham group 
A
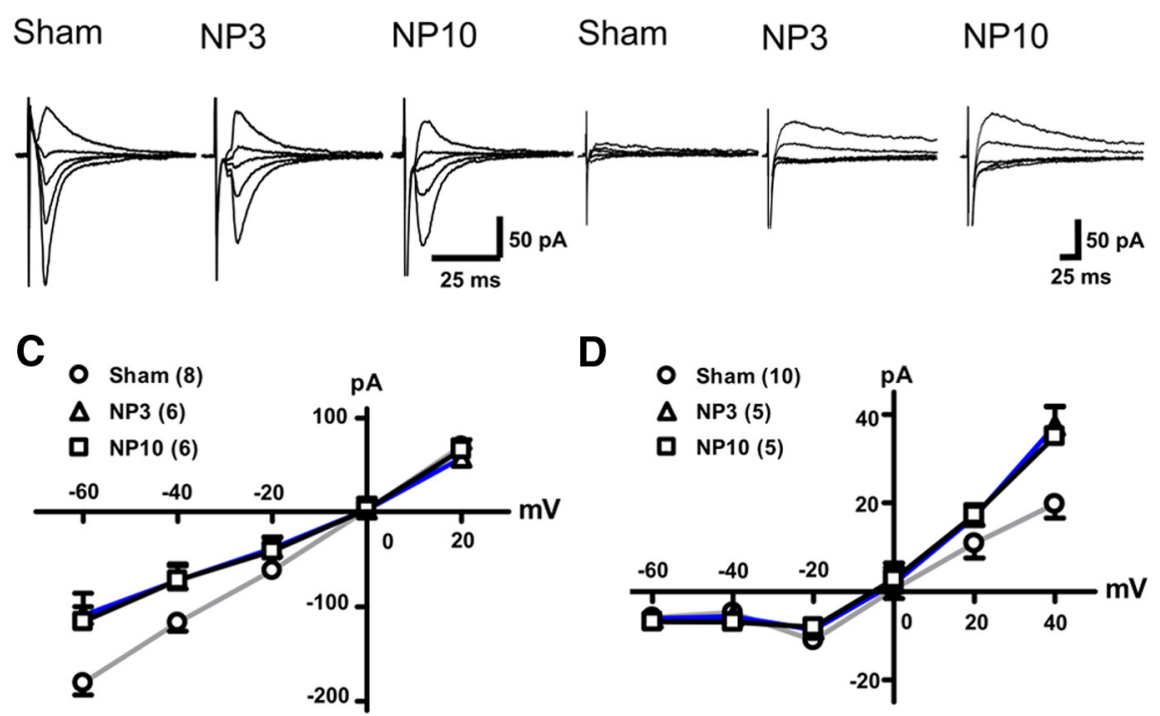

E

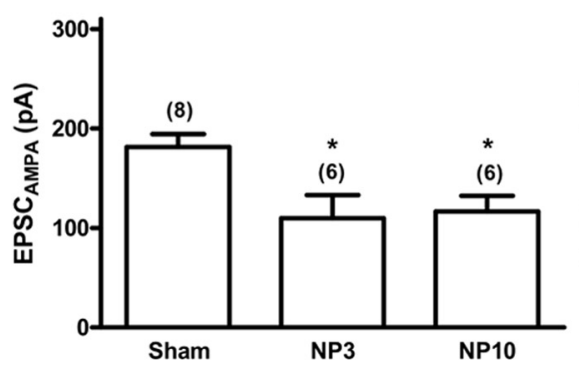

D

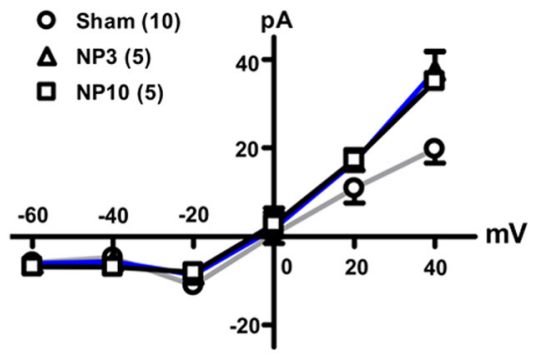

F

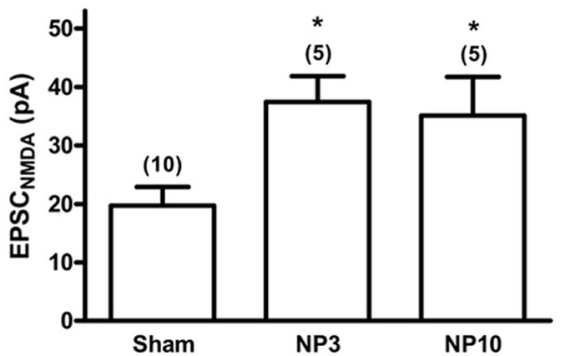

Figure 6. $S N L$ resulted in reduced $E P S C_{A M P A} S$ and enhanced $E P S C_{N M D A} S$ in vIPAG slices. $E P S C_{A M P A}$ s were recorded with $50 \mu \mathrm{M}$

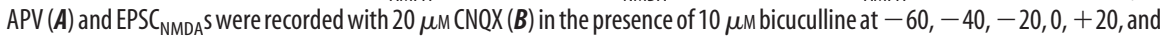
$+40 \mathrm{mV}$. The $\boldsymbol{I}-\boldsymbol{V}$ curves of EPSC ${ }_{A M P A} S(\boldsymbol{C})$ and $\operatorname{EPSC}_{\mathrm{NMDA}} \mathrm{S}(\boldsymbol{D})$ in sham $(\bigcirc$; gray line), NP3 ( $\triangle$; blue line), and NP10 ( $\square$; black line)

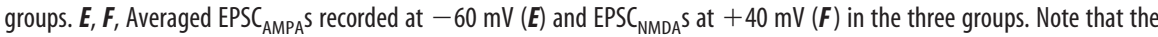
EPSC $_{\text {AMPA }}$ was significantly smaller $\left(F_{(2,17)}=5.742\right.$, one-way ANOVA, $\left.p<0.05\right)$ but the $\operatorname{EPSC}_{\text {NMDA }}$ was larger $\left(F_{(2,17)}=5.369\right.$, one-way ANOVA, $p<0.05$ ) in the NP groups than in the sham group. ${ }^{*} p<0.05$ compared with the sham group (post hoc Dunnett's test).

(Fig. 5B, $D, F$ ). Similarly, no significant difference in NMDAinduced currents was observed between the NP3 and NP10 groups. These results suggest that the AMPAR response to exogenous ligand is decreased but the NMDAR response is enhanced after SNL.

Reduced $E P S C_{A M P A} s$ and enhanced $E P S C_{N M D A}$ s in the NP groups The finding that SNL inversely altered the responses of AMPARs and NMDARs to their respective exogenous ligands is interesting. We further examined whether SNL also affected the responses of glutamate receptors in the vlPAG to the endogenous ligand glutamate, which mediates EPSCs. $\mathrm{EPSC}_{\mathrm{AMPA}} \mathrm{S}$ and EPSC $_{\text {NMDA }} \mathrm{s}$ evoked by local stimulation can be isolated by APV ( 50 $\mu \mathrm{M})$ and CNQX $(20 \mu \mathrm{M})$, respectively, in the presence of bicuculline (10 $\mu \mathrm{M}$; Chiou and Chou, 2000). As shown in Figure 6A, C, E, EPSC $_{\mathrm{AMPA}} \mathrm{s}$ in both the NP3 and NP10 groups were significantly smaller than those in the sham group. The reversal potential of the $I-V$ curve of $\mathrm{EPSC}_{\mathrm{AMPA}} \mathrm{s}$ in the sham group, being $\sim 0 \mathrm{mV}$, was not significantly different from that in either the NP3 or NP10 group (Fig. 6C). The average amplitudes of $\mathrm{EPSC}_{\mathrm{AMPA}} \mathrm{S}$ recorded at $-60 \mathrm{mV}$, as demonstrated in Figure $6 E$, in the NP3 and NP10 groups were significant smaller than that in the sham group (Fig. $6 E$ ).

EPSC $_{\text {NMDA }} s$ in both the NP3 and NP10 groups were larger than those in the sham group, unlike $\mathrm{EPSC}_{\mathrm{AMPA}} \mathrm{s}$, which were smaller (Fig. 6B). The reversal potential of the $I-V$ curve of EPSC $_{\text {NMDA }} s$ in the sham group, being $\sim 0 \mathrm{mV}$, was also not significantly different from that in either the NP3 or NP10 group (Fig. 6D). The average amplitudes of EPSC $\mathrm{NMDA}_{\mathrm{N}} \mathrm{s}$ recorded at $+40 \mathrm{mV}$ in the NP3 and NP10 groups were significant larger than those in the sham group (Fig. $6 F$ ). Neither EPSC $_{\mathrm{AMPA} \mathrm{S}}$ (Fig. 6E) nor EPSC NMDA s (Fig. $6 F$ ) of the NP3 and NP10 groups were significantly different. These results confirm that SNL led to decreased AMPAR response and enhanced NMDAR response to both exogenous and endogenous ligands.

We further compared the ratio of $\mathrm{EPSC}_{\mathrm{AMPA}} / \mathrm{EPSC}_{\mathrm{NMDA}}$ in the same neuron with the same stimulation voltage, which corrects the variations from presynaptic release conditions due to different stimulation voltages among slices. In the presence of $10 \mu \mathrm{M}$ bicuculline, $\mathrm{EPSC}_{\mathrm{AMPA}} \mathrm{s}$ (Fig. 7A, downward deflection) were recorded at $-70 \mathrm{mV}$ first, and then in the same neuron the EPSC $_{\mathrm{NMDA} \mathrm{s}}$ (Fig. $7 A$, upward deflection) were recorded at $+40 \mathrm{mV}$ after further addition of $20 \mu \mathrm{M}$ CNQX. The ratios of $\mathrm{EPSC}_{\mathrm{AMPA}} / \mathrm{EPSC}_{\mathrm{NMDA}}$ in the NP3 and NP10 groups were significantly lower than that in the sham group (Fig. $7 B$ ), whereas there was no significant difference between the NP3 and NP10 groups ( $p>$ 0.05 ; Fig. $7 B$ ).

To investigate whether the neuroplastic change in the vlPAG is injury-side specific, we compared changes of EPSC $_{\text {AMPA }}$ / EPSC $_{\text {NMDA }}$ ratio in the vlPAG ipsilateral and contralateral to the injury side in neuropathic rats. The ratios of $\mathrm{EPSC}_{\mathrm{AMPA}} / \mathrm{EPSC}_{\mathrm{NMDA}}$ in ipsilateral and contralateral vlPAG neurons were not different in either the NP3 (ipsilateral: $1.92 \pm$ 1.22, $n=3$; contralateral: $1.79 \pm 0.27, n=6 ; p>0.05$ ) or NP10 (ipsilateral: $2.49 \pm 0.4, n=4$; contralateral: $1.86 \pm 0.61, n=5$; $p>0.05)$ group, whereas they were significantly lower than the ratio of $\mathrm{EPSC}_{\mathrm{AMPA}} / \mathrm{EPSC}_{\mathrm{NMDA}} 5.7 \pm 1.03(n=12)$ in the sham group. This suggests that unilateral SNL causes bilateral impairment of glutamatergic neurotransmission in the vlPAG.

Upregulation of NR1 and NR2 subunits of NMDARs, but not the GluR1 or GluR2 subunit of AMPARs, in neuropathic rats The changes in AMPAR and NMDAR responses can be attributed to an alteration in receptor expression, receptor sensitivity, and/or receptor function (Perkel and Nicoll, 1993). Therefore, we further quantified the protein levels of the constitutive subunits of the AMPARs GluR1 and GluR2 and the NMDARs NR1, NR2A, and NR2B in the vlPAG region of three groups of rats. The protein level of either the GluR1 (Fig. 8A) or the GluR2 (Fig. 8B) subunit of AMPARs in the vlPAG of the NP3 or NP10 group was 
A

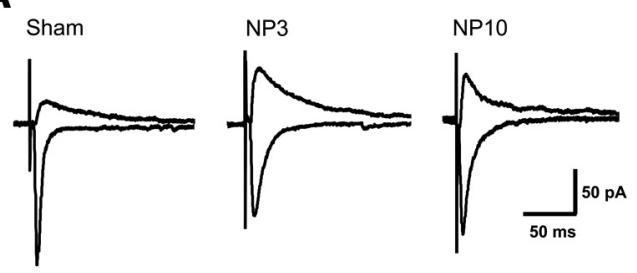

B

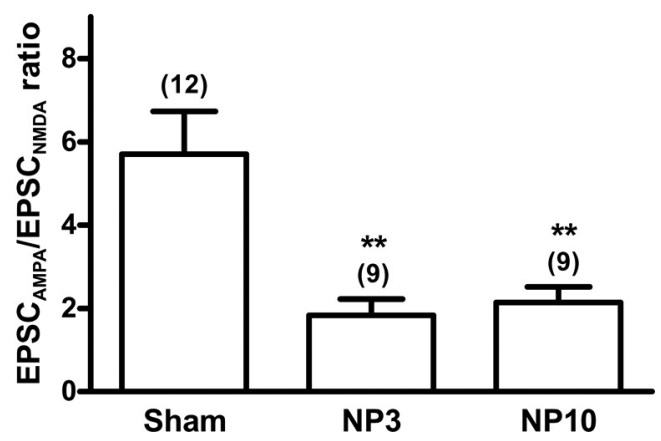

Figure 7. The ratio of $E P S C_{A M P A} / E{ }^{2} C_{\text {NMDA }}$ recorded from the same neuron was significantly reduced in the vIPAG of rats after $S N L$. The EPSC $C_{A M P A}$ s and $E P S C_{N M D A}$ S were recorded in the same neuron at -70 and $+40 \mathrm{mV}$, respectively. $A$, Representative trace of $\mathrm{EPSC}_{\mathrm{AMPA}} \mathrm{S}$ (downward) and $E P S C_{N M D A} S$ (upward) recorded from a vIPAG neuron of the slice dissected from the sham, NP3, and NP10 groups. $B$, Averaged ratio of EPSC AMPA $_{\text {EPSC }}$ NMDA in the sham, NP3, and NP10 groups. The average of the ratio of $E{ } C_{A M P A} / E P S C_{N M D A}$, which was calculated from each recorded neuron, in the NP groups was significantly lower than in the sham group $\left(F_{(2,27)}=\right.$ 8.354 , one-way ANOVA, $p<0.01$ ). ${ }^{* *} p<0.01$ compared with the sham group (post hoc Dunnett's test).

not significantly different from that in the sham group. However, the expression levels of the NR1 (Fig. 8C) and NR2B (Fig. 8D), but not the NR2A (Fig. 8E), subunits of NMDARs in the vlPAG were significantly higher in both the NP3 and NP10 groups than in the sham group. These results suggest that the increased NMDAR response in the vlPAG after SNL is attributed to an upregulation of NR1 and NR2B proteins, whereas the decreased AMPAR response is due to a decrease in the function, but not protein level, of AMPARs.

\section{SNL results in longer EPSC latency and lower excitability in vlPAG neurons}

The latencies of EPSCs in vlPAG slices in both the NP3 and NP10 groups were longer than that in the sham group (Fig. 2, traces). Although the latency varied depending on the distance between stimulation and recording electrodes, we kept it within 50-200 $\mu \mathrm{m}$ in each slice and plotted the distribution of the latency of the EPSC recorded from all experiments described above in Figure $9 A$. The averaged latencies of EPSCs in the NP3 (4.04 $\pm 0.29 \mathrm{~ms}$, $n=25)$ and NP10 (3.82 $\pm 0.29, n=22)$ groups were significantly longer $(2.90 \pm 0.21 \mathrm{~ms}, n=23)$ than that in the sham group, whereas there was no significant difference between the NP3 and NP10 groups. Therefore, SNL may lead to nerve conduction block in glutamatergic transmission in the vlPAG.

We further examined whether the neuronal excitability in the NP groups was reduced, which may lead to conduction block. Indeed, the neuronal excitability, as measured by the number of action potentials elicited by injecting a depolarizing current, was significantly lower in either the NP3 or NP10 group than in the control group (Fig. 9B). The numbers of action potentials induced by a $60 \mathrm{nA}$-current injection for $200 \mathrm{~ms}$ in both the NP3
$(1.92 \pm 0.65, n=12)$ and NP10 $(1.8 \pm 0.81, n=15)$ groups were significantly lower than that $(7.82 \pm 1.03, n=11)$ in the sham group $\left(F_{(2,35)}=15.76\right.$, one-way ANOVA, $p<0.0001$, post hoc Dunnett's test comparisons). However, the passive membrane properties, including the membrane potential (sham: $-67.9 \pm$ $2.3 \mathrm{mV}, n=11$; NP3: $-66.34 \pm 3.5 \mathrm{mV}, n=12$; NP10: $-67.29 \pm$ $2.8 \mathrm{mV}, n=15$ ), input resistance (sham: $780 \pm 76 \mathrm{M} \Omega, n=11$; NP3: $792 \pm 94 \mathrm{M} \Omega, n=12$; NP10: $782 \pm 97 \mathrm{M} \Omega, n=15)$, and membrane capacitance (sham: $48.9 \pm 5.1 \mathrm{pF}, n=11$; NP3: $39.9 \pm 3.8 \mathrm{pF}, n=12$; NP10: $47.0 \pm 4.8 \mathrm{pF}, n=15)$ were not significantly different among these three groups.

\section{Discussion}

In this study, we found reduced glutamate release and an impaired AMPAR response in the vlPAG of neuropathic rats 3 and $10 \mathrm{~d}$ after SNL. These neuroplastic changes may result in hypofunction of glutamatergic neurotransmission in the vlPAG and reduction of descending pain inhibition, which may contribute to the initiation and maintenance of neuropathic pain.

\section{Hypofunction of glutamatergic neurotransmission is} attributed to both presynaptic and postsynaptic mechanisms The reduced I-O relationship of EPSCs in the NP groups suggests that SNL induced hypofunctioning of glutamatergic neurotransmission in the vlPAG, which may be attributed to both presynaptic and postsynaptic mechanisms. The findings of higher PPR and lower mEPSC frequency in the NP groups compared with the sham group support the contribution of presynaptic reduction of glutamate release in this hypofunctioning of neurotransmission. In the vlPAG, EPSCs are mainly mediated by AMPARs (Chiou and Chou, 2000). The findings of smaller EPSCs, mEPSCs, EPSC $_{\mathrm{AMPA}} \mathrm{s}$, and AMPA currents in the NP groups suggest that SNL results in postsynaptic impairment of AMPAR function in the vlPAG, because the expression of the AMPAR subunits was not altered.

\section{Hypofunction of glutamatergic neurotransmission in the vlPAG results in decreased descending pain inhibition, leading to neuropathic pain}

Activation of the vlPAG initiates the descending inhibitory pathway, leading to antinociception (Millan, 2002; Heinricher et al., 2009). It has been reported that the projection neurons in the vlPAG form excitatory connections with OFF-cells in the RVM (Morgan et al., 2008), activation of which is associated with antinociceptive behaviors (Tortorici and Morgan, 2002; Maione et al., 2006). Therefore, hypofunctioning of glutamatergic neurotransmission in the vlPAG after nerve injury may lead to reduced OFF-cell activity in the RVM and thus decreased descending inhibition onto the spinal dorsal horn, leading to neuropathic pain.

In various pain models, long-term neuroplastic changes in glutamatergic transmission have been reported in the spinal cord and several supraspinal pain-related nuclei, including the RVM, amygdala, and ACC (Seltzer et al., 1991; Coutinho et al., 1998; Neugebauer et al., 2003; Wu et al., 2005; Iwata et al., 2007; Xu et al., 2008; Zhang and Hammond, 2009; Da Silva et al., 2010). However, all of these studies found hyperfunctioning of glutamatergic transmission in these pain-related regions, which leads to increased descending pain facilitation. This is in contrast to our finding in a neuropathic pain model that glutamatergic transmission in the vlPAG was decreased, resulting in decreased descending pain inhibition. 
A
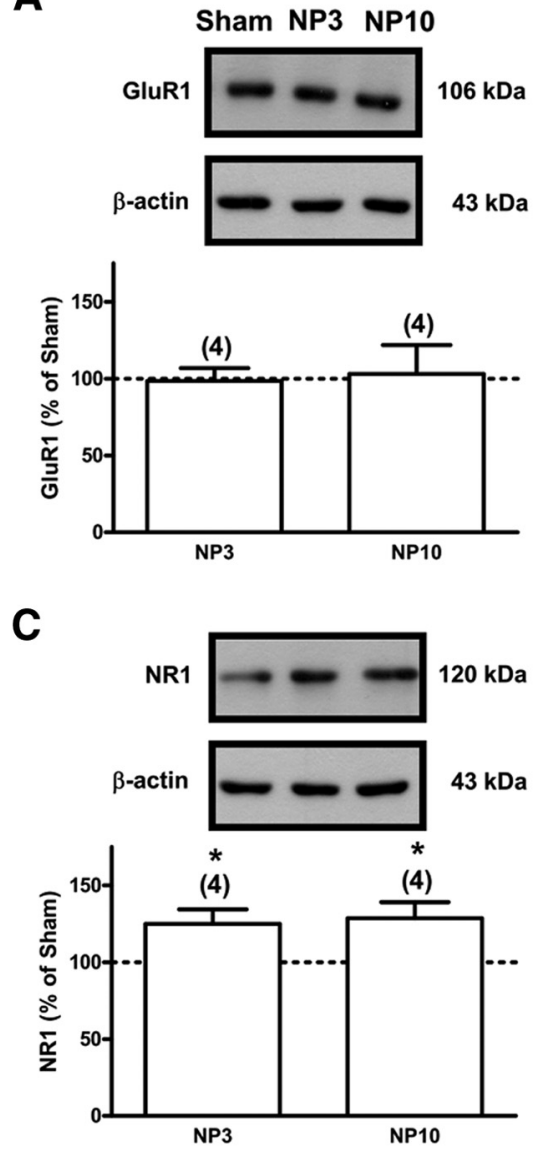

B
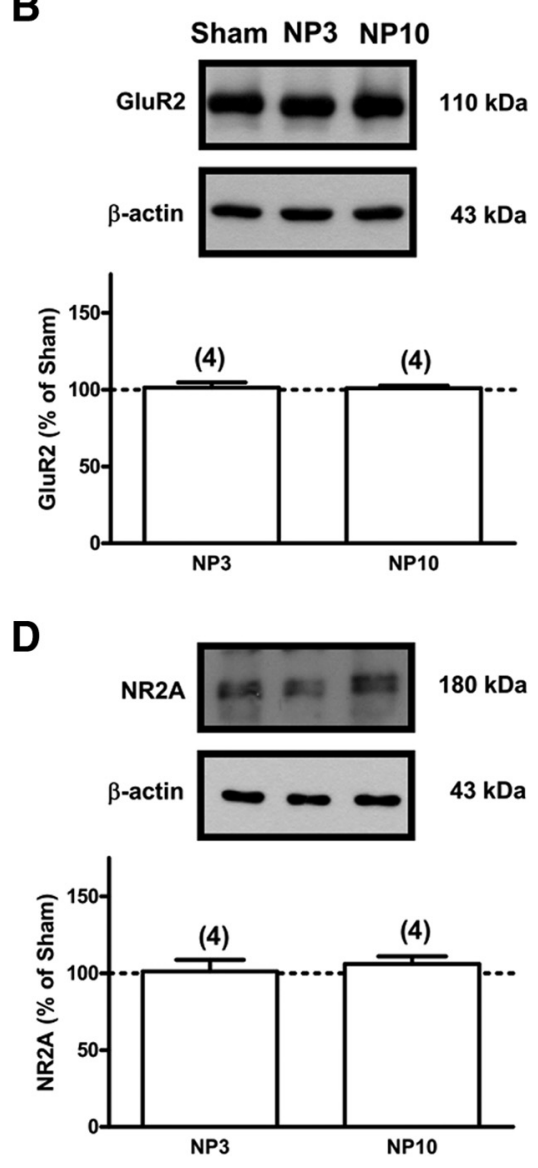

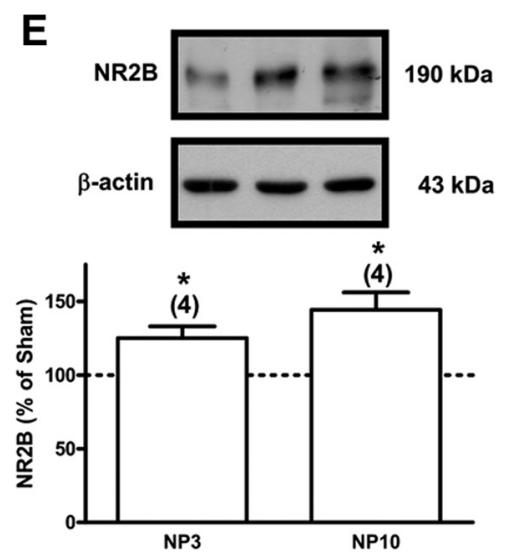

Figure 8. SNL resulted in upregulation of the NR1 and NR2B subunits of NMDARs, but not the GluR1 or GluR2 subunit of AMPARs in the vIPAG. Representative Western blots and summarized bar graphs depicting the expression level of GluR1 (A), GluR2 (B), NR1 $(\boldsymbol{C}), \mathrm{NR2A}(\boldsymbol{D})$, or NR2B $(\boldsymbol{E})$ subunit protein in vIPAG samples micropunched from sham, NP3, and NP10 rats. The top blots are the immunoreactive bands against the respective antibody against the GluR1, GluR2, NR1, NR2A, or NR2B subunit protein and the bottom blots are the bands for the housekeeping protein $\beta$-actin. The ordinate of the base graph is the expression level of the receptor protein, taking the sham group as $100 \%{ }^{*} p<0.05$ compared with the sham group as $100 \%$ (one-sample $t$ test).

\section{Neuroplastic changes of glutamate receptors in chronic pain models \\ NMDARs}

The findings of upregulation of the NR1 and NR2B subunits, but not the NR2A subunits, of postsynaptic NMDARs may explain the increased EPSC $_{\mathrm{NMDA}} \mathrm{s}$ and NMDA currents in the vlPAG of neuropathic rats. Although we did not reconfirm the specificity of the antibodies used, the same findings in NMDAR subunit changes have also been reported in the PAG of mice after SNL
(Renno, 1998) or inflamed with complete Freund's adjuvant (CFA; Renno, 1998; $\mathrm{Hu}$ et al., 2009). We found upregulated NMDARs and reduced glutamate release in the vlPAG in the same neuropathic pain model. Glutamate release reduction could be the cause or effect of NMDAR upregulation after SNL. If it were the cause, then AMPARs might also be upregulated. Because AMPARs were not upregulated in the NP groups, it is more likely that reduced glutamate release is a compensatory change due to NMDAR upregulation.

Upregulation of the NR2B subunit, but not the NR2A subunit, was also found in the ACC of CFA-inflamed mice (Wu et al., 2005) and in the mouse spinal dorsal horn after SNL (Iwata et al., 2007). In the RVM, increased NR2A subunit phosphorylation in CFA-inflamed rats (Guo et al., 2006), increased NR1 subunit phosphorylation via glial-neuronal interactions in rats with infraorbital nerve injury (Wei et al., 2008), and NR1 subunit upregulation in an acid-induced muscle pain model (Da Silva et al., 2010) have been reported to contribute to descending pain facilitation. However, NMDAR subunit upregulations or phosphorylation in these areas, unlike the PAG, may increase nociceptive responses. Compared with other NR2 subunits, the NR2B and NR1 subunits seem to be more vulnerable to being upregulated.

The NMDAR, especially the NR2B subunit, in the vlPAG has been suggested to be involved in pain processing, because CFA-induced inflammatory pain was blocked by intra-PAG injection of a selective NR2B blocker (Hu et al., 2009). Similarly, NMDAR activation in the RVM was also implicated in mediating nociceptive responses in inflammatory (Urban et al., 1999; Guan et al., 2002) and visceral (Coutinho et al., 1998) pain models. In the spinal dorsal horn, NMDAR activation is also believed to mediate neuropathic pain (Iwata et al., 2007). Therefore, NMDAR may contribute to long-term changes in pain processing whether as a cause or an effect.

In this study, upregulated NR1 and NR2B subunits may have resulted in excitotoxicity due to intracellular calcium overload through excessive activation of NMDARs (Choi, 1988), leading to neuronal loss in the vlPAG after SNL. Neuronal loss is suggested from the findings of prolonged EPSC latency (possibly due to conduction block) and fewer healthy neurons recorded in the NP groups. The NMDAR-mediated neuronal loss has been attributed to several neurological disorders, including pain (Whiteside and Munglani, 2001; Leong et al., 2011; Mor et al., 2011). Neuronal loss of OFF-cells in the RVM (Leong et al., 
A

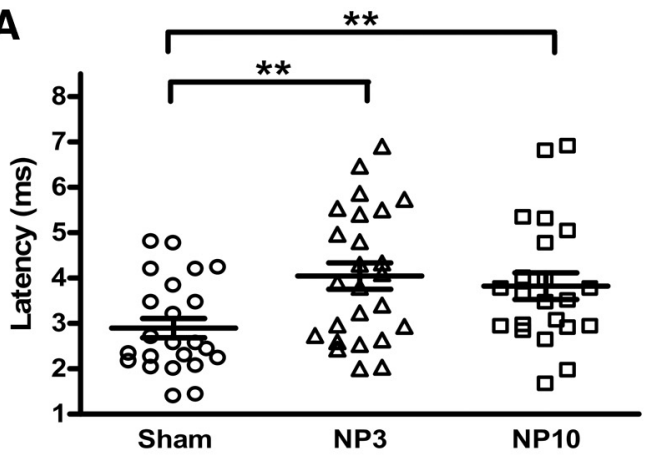

B
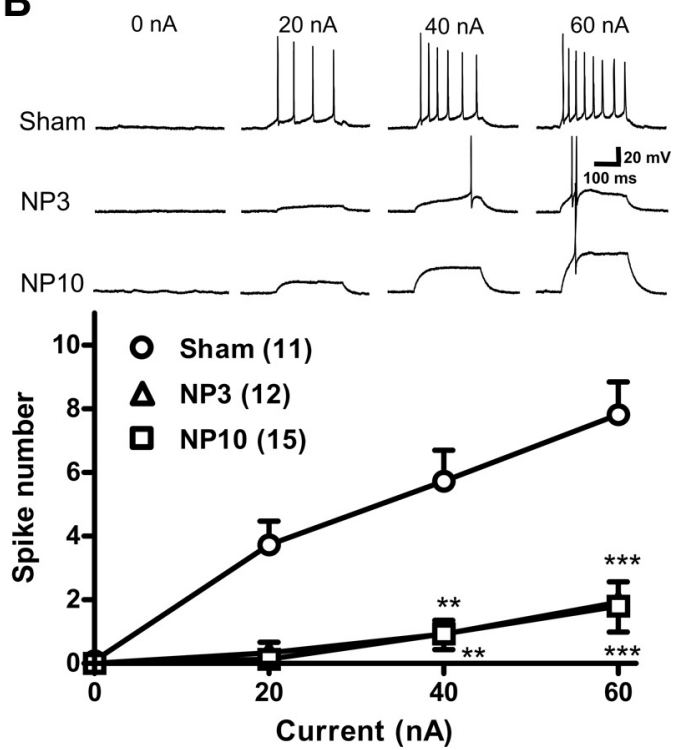

Figure 9. SNL resulted in a prolongation of the latency of EPSCS in vIPAG slices. $A$, Latency of the EPSC measured as the time difference between the stimulation artifact and the takeoff of EPSC in the sham $(O), N P 3(\triangle)$, and NP10 $(\square)$ groups. Each data point represents the latency of one EPSC recorded in a neuron from the sham, NP3, and NP10 groups $\left(F_{(2,67)}=5.137\right.$, one-way ANOVA, $p<0.01$ ). ${ }^{* *} p<0.01$ compared with the sham group (post hoc Dunnett's test). $\boldsymbol{B}$, Whole-cell current-clamp recordings of action potentials generated by current injection in vIPAG neuron of the sham, NP3, and NP10 groups. Top: Representative recordings of action potentials induced by a current of $0,20,40$, and $60 \mathrm{nA}$ for $200 \mathrm{~ms}$ in the sham, NP3, and NP10 groups. Bottom: Averaged spike number induced by current injection in vIPAG sham $(\bigcirc)$, NP3 $(\triangle)$, and NP10 $(\square)$ groups. Two-way ANOVA with repeated measures over current analysis indicated significant differences with a main effect of group $\left(F_{(2,105)}=20.11 ; p<0.0001\right)$ and of current $\left(F_{(3,105)}=47.14 ; p<0.0001\right)$, and in the interaction of group by current $\left(F_{(6,105)}=12.08 ; p<0.0001\right) .{ }^{* *} p<0.01,{ }^{* * *} p<0.001$ compared with the sham group (post hoc Bonferroni's comparisons of the data points denoted).

2011), GABAergic neurons in the spinal dorsal horn (Whiteside and Munglani, 2001; Moore et al., 2002), and possibly glutamatergic neurons in the PAG (Mor et al., 2011) have been reported in various neuropathic pain models.

\section{AMPARs}

The smaller EPSC $\mathrm{AMPA}_{\mathrm{AM}} \mathrm{s}$ and AMPA currents observed in vlPAG slices from neuropathic rats could have been due to downregulation or endocytosis of AMPARs or to reduced sensitivity or efficacy of AMPARs. The findings of unaltered GluR1 and GluR2 immunoreactivity suggest no downregulation or intracellular degradation of AMPARs in the vlPAG of neuropathic rats. Although the total number of AMPARs was not changed, there might be a subcellular redistribution of AMPARs. In the hippocampus, intracellular calcineurin activation after NMDAR activation can lead to a clathrin-dependent internalization of
AMPARs (Beattie et al., 2000; Carroll et al., 2001). Jarzylo and Man (2012) also demonstrated that stimulation of NR2BNMDARs induced AMPAR internalization in cortical and hippocampal neurons. Activation of the vlPAG of neuropathic rats with more available NMDARs may lead to internalization of AMPARs. Postsynaptic AMPAR trafficking is involved in the learning, memory, and synaptic plasticity of the hippocampus (Malinow and Malenka, 2002; Sheng and Kim, 2002; Bredt and Nicoll, 2003). It remains to be elucidated whether postsynaptic AMPAR redistribution, which may occur after nerve injury, contributes to the synaptic plasticity of the vlPAG, leading to hypersensitive behaviors.

\section{Neuroplastic changes in the vlPAG during the development and maintenance of neuropathic pain}

Burgess et al. (2002) found a descending pain facilitation mechanism originated from the RVM at $6 \mathrm{~d}$, but not $3 \mathrm{~d}$, after SNL, and proposed that this mechanism may contribute to the maintenance of neuropathic pain but not the initiation phase, which was considered to have originated from afferent ectopic discharges (Han et al., 2000). However, the neuroplastic changes in the mouse ACC may contribute to both the development and maintenance of chronic pain, because upregulation of glutamate receptor was found after $3 \mathrm{~d}$ (Wu et al., 2005) and $7 \mathrm{~d}$ (Xu et al., 2008), respectively, in inflammatory and neuropathic pain models. In the vlPAG, we found neuroplastic changes $3 \mathrm{~d}$ after SNL, which lasted for at least $10 \mathrm{~d}$. Similarly, in the PAG, upregulation of NR2B subunits occurred $3 \mathrm{~d}$ after hindpaw CFA injection ( $\mathrm{Hu}$ et al., 2009) and an increased $\mathrm{EPSC}_{\mathrm{NMDA}} / \mathrm{EPSC}_{\text {non-NMDA }}$ ratio occurred $5 \mathrm{~d}$ after sciatic nerve ligation (Terashima et al., 2012). These results suggest that neuroplastic changes in the PAG, which lead to decreased descending pain inhibition, contribute to both the development and maintenance of neuropathic pain.

\section{Unilateral peripheral injury induces bilateral changes in the PAG}

The findings that unilateral SNL led to ipsilateral mechanical hypersensitivity but bilateral neuroplastic changes in the vlPAG may have been due to the fact that the PAG is a midline structure that receives input projections in the bulbospinal tract from both sides of the body and extremities (Wiberg et al., 1987; Lima and Coimbra, 1989). Similarly, unilateral peripheral injury induced bilateral changes in the vlPAG were also reported in inflammatory and neuropathic pain models (Renno, 1998) and in the ACC in an amputation pain model (Wei et al., 1999). Unilateral SNL also led to comprehensive neuroplastic changes that were not injury-side specific in the RVM, which is also a midline nucleus (Gonçalves et al., 2007). Burgess et al. (2002) showed that bilateral lesions of the dorsolateral funiculus completely reversed ipsilateral SNL-induced mechanical hypersensitivity/hyperalgesia, suggesting an important role of bilateral descending pain modulation in maintaining neuropathic pain.

In conclusion, SNL resulted in bilateral long-lasting hypofunctioning of glutamatergic neurotransmission in the vlPAG due to reduced glutamate release and impaired AMPAR response, which may result from upregulation of NR1 and NR2B subunits, leading to AMPAR internalization and possible neuronal loss. This SNL-induced hypoglutamatergic neurotransmission in the PAG may impair descending pain inhibition and contribute to the development and maintenance of neuropathic pain. 


\section{References}

Bagley EE, Gerke MB, Vaughan CW, Hack SP, Christie MJ (2005) GABA transporter currents activated by protein kinase A excite midbrain neurons during opioid withdrawal. Neuron 45:433-445. CrossRef Medline

Basbaum AI, Fields HL (1984) Endogenous pain control systems: brainstem spinal pathways and endorphin circuitry. Annu Rev Neurosci 7:309-338. CrossRef Medline

Beattie EC, Carroll RC, Yu X, Morishita W, Yasuda H, von Zastrow M, Malenka RC (2000) Regulation of AMPA receptor endocytosis by a signaling mechanism shared with LTD. Nat Neurosci 3:1291-1300. CrossRef Medline

Bredt DS, Nicoll RA (2003) AMPA receptor trafficking at excitatory synapses. Neuron 40:361-379. CrossRef Medline

Burgess SE, Gardell LR, Ossipov MH, Malan TP Jr, Vanderah TW, Lai J, Porreca F (2002) Time-dependent descending facilitation from the rostral ventromedial medulla maintains, but does not initiate, neuropathic pain. J Neurosci 22:5129-5136. Medline

Carlson JD, Maire JJ, Martenson ME, Heinricher MM (2007) Sensitization of pain-modulating neurons in the rostral ventromedial medulla after peripheral nerve injury. J Neurosci 27:13222-13231. CrossRef Medline

Carroll RC, Beattie EC, von Zastrow M, Malenka RC (2001) Role of AMPA receptor endocytosis in synaptic plasticity. Nat Rev Neurosci 2:315-324. CrossRef Medline

Chaplan SR, Bach FW, Pogrel JW, Chung JM, Yaksh TL (1994) Quantitative assessment of tactile allodynia in the rat paw. J Neurosci Methods 53:55-63. CrossRef Medline

Cheng JK, Chou RC, Hwang LL, Chiou LC (2003) Antiallodynic effects of intrathecal orexins in a rat model of postoperative pain. J Pharmacol Exp Ther 307:1065-1071. CrossRef Medline

Chiou LC, Chou HH (2000) Characterization of synaptic transmission in the ventrolateral periaqueductal gray of rat brain slices. Neuroscience 100:829-834. CrossRef Medline

Chiou LC, Huang LY (1999) Mechanism underlying increased neuronal activity in the rat ventrolateral periaqueductal grey by a mu-opioid. J Physiol 518:551-559. CrossRef Medline

Choi DW (1988) Glutamate neurotoxicity and diseases of the nervous system. Neuron 1:623-634. CrossRef Medline

Chu LC, Tsaur ML, Lin CS, Hung YC, Wang TY, Chen CC, Cheng JK (2011) Chronic intrathecal infusion of gabapentin prevents nerve ligationinduced pain in rats. Br J Anaesth 106:699-705. CrossRef Medline

Coutinho SV, Urban MO, Gebhart GF (1998) Role of glutamate receptors and nitric oxide in the rostral ventromedial medulla in visceral hyperalgesia. Pain 78:59-69. CrossRef Medline

Da Silva LF, Walder RY, Davidson BL, Wilson SP, Sluka KA (2010) Changes in expression of NMDA-NR1 receptor subunits in the rostral ventromedial medulla modulate pain behaviors. Pain 151:155-161. CrossRef Medline

Fields HL, Anderson SD, Clanton CH, Basbaum AI (1976) Nucleus raphe magnus: a common mediator of opiate- and stimulus-produced analgesia. Trans Am Neurol Assoc 101:208-210. Medline

Gonçalves L, Almeida A, Pertovaara A (2007) Pronociceptive changes in response properties of rostroventromedial medullary neurons in a rat model of peripheral neuropathy. Eur J Neurosci 26:2188-2195. CrossRef Medline

Guan Y, Terayama R, Dubner R, Ren K (2002) Plasticity in excitatory amino acid receptor-mediated descending pain modulation after inflammation. J Pharmacol Exp Ther 300:513-520. CrossRef Medline

Guo W, Robbins MT, Wei F, Zou S, Dubner R, Ren K (2006) Supraspinal brain-derived neurotrophic factor signaling: a novel mechanism for descending pain facilitation. J Neurosci 26:126-137. CrossRef Medline

Han HC, Lee DH, Chung JM (2000) Characteristics of ectopic discharges in a rat neuropathic pain model. Pain 84:253-261. CrossRef Medline

Heinricher MM, Tavares I, Leith JL, Lumb BM (2009) Descending control of nociception: Specificity, recruitment and plasticity. Brain Res Rev 60: 214-225. CrossRef Medline

Ho YC, Lee HJ, Tung LW, Liao YY, Fu SY, Teng SF, Liao HT, Mackie K, Chiou LC (2011) Activation of orexin 1 receptors in the periaqueductal gray of male rats leads to antinociception via retrograde endocannabinoid (1-arachidonoylglycerol)-induced disinhibition. J Neurosci 31:1460014610. CrossRef Medline

Hu J, Wang Z, Guo YY, Zhang XN, Xu ZH, Liu SB, Guo HJ, Yang Q, Zhang FX, Sun XL, Zhao MG (2009) A role of periaqueductal grey NR2B- containing NMDA receptor in mediating persistent inflammatory pain. Mol Pain 5:71. CrossRef Medline

Iwata H, Takasusuki T, Yamaguchi S, Hori Y (2007) NMDA receptor 2B subunit-mediated synaptic transmission in the superficial dorsal horn of peripheral nerve-injured neuropathic mice. Brain Res 1135:92-101. CrossRef Medline

Jarzylo LA, Man HY (2012) Parasynaptic NMDA receptor signaling couples neuronal glutamate transporter function to AMPA receptor synaptic distribution and stability. J Neurosci 32:2552-2563. CrossRef Medline

Lee CY, Lee CH, Shih CC, Liou HH (2008) Paraquat inhibits postsynaptic AMPA receptors on dopaminergic neurons in the substantia nigra pars compacta. Biochem Pharmacol 76:1155-1164. CrossRef Medline

Leong ML, Gu M, Speltz-Paiz R, Stahura EI, Mottey N, Steer CJ, Wessendorf M (2011) Neuronal loss in the rostral ventromedial medulla in a rat model of neuropathic pain. J Neurosci 31:17028-17039. CrossRef Medline

Liao HT, Lee HJ, Ho YC, Chiou LC (2011) Capsaicin in the periaqueductal gray induces analgesia via metabotropic glutamate receptormediated endocannabinoid retrograde disinhibition. Br J Pharmacol 163:330-345. CrossRef Medline

Lima D, Coimbra A (1989) Morphological types of spinomesencephalic neurons in the marginal zone (lamina I) of the rat spinal cord, as shown after retrograde labelling with cholera toxin subunit B. J Comp Neurol 279:327-339. CrossRef Medline

Liu X, Eschenfelder S, Blenk KH, Jänig W, Häbler H (2000) Spontaneous activity of axotomized afferent neurons after L5 spinal nerve injury in rats. Pain 84:309-318. CrossRef Medline

Maione S, Bisogno T, de Novellis V, Palazzo E, Cristino L, Valenti M, Petrosino S, Guglielmotti V, Rossi F, Di Marzo V (2006) Elevation of endocannabinoid levels in the ventrolateral periaqueductal grey through inhibition of fatty acid amide hydrolase affects descending nociceptive pathways via both cannabinoid receptor type 1 and transient receptor potential vanilloid type-1 receptors. J Pharmacol Exp Ther 316:969-982. CrossRef Medline

Malinow R, Malenka RC (2002) AMPA receptor trafficking and synaptic plasticity. Annu Rev Neurosci 25:103-126. CrossRef Medline

Millan MJ (2002) Descending control of pain. Prog Neurobiol 66:355-474. CrossRef Medline

Moore KA, Kohno T, Karchewski LA, Scholz J, Baba H, Woolf CJ (2002) Partial peripheral nerve injury promotes a selective loss of GABAergic inhibition in the superficial dorsal horn of the spinal cord. J Neurosci 22:6724-6731. Medline

Mor D, Bembrick AL, Austin PJ, Keay KA (2011) Evidence for cellular injury in the midbrain of rats following chronic constriction injury of the sciatic nerve. J Chem Neuroanat 41:158-169. CrossRef Medline

Morgan MM, Whittier KL, Hegarty DM, Aicher SA (2008) Periaqueductal gray neurons project to spinally projecting GABAergic neurons in the rostral ventromedial medulla. Pain 140:376-386. CrossRef Medline

Neugebauer V, Li W, Bird GC, Bhave G, Gereau RW 4th (2003) Synaptic plasticity in the amygdala in a model of arthritic pain: differential roles of metabotropic glutamate receptors 1 and 5. J Neurosci 23:52-63. Medline

Perkel DJ, Nicoll RA (1993) Evidence for all-or-none regulation of neurotransmitter release: implications for long-term potentiation. J Physiol 471:481-500. Medline

Renno WM (1998) Prolonged noxious stimulation increases periaqueductal gray NMDA mRNA expression: a hybridization study using two different rat models for nociception. Neurobiology (Bp) 6:333-357. Medline

Sandkühler J (2009) Models and mechanisms of hyperalgesia and allodynia. Physiol Rev 89:707-758. CrossRef Medline

Seltzer Z, Cohn S, Ginzburg R, Beilin B (1991) Modulation of neuropathic pain behavior in rats by spinal disinhibition and NMDA receptor blockade of injury discharge. Pain 45:69-75. CrossRef Medline

Sheng JG, Price DL, Koliatsos VE (2002) Disruption of corticocortical connections ameliorates amyloid burden in terminal fields in a transgenic model of Abeta amyloidosis. J Neurosci 22:9794-9799. Medline

Sheng M, Kim MJ (2002) Postsynaptic signaling and plasticity mechanisms. Science 298:776-780. CrossRef Medline

Terashima T, Shirakawa K, Maekawa M, Furukawa N, Yamaguchi S, Hori Y (2012) Differential expression of NMDA receptors in serotonergic and/or GABAergic neurons in the midbrain periaqueductal gray of the mouse. Neurosci Lett 528:55-60. CrossRef Medline

Tortorici V, Morgan MM (2002) Comparison of morphine and kainic acid 
microinjections into identical PAG sites on the activity of RVM neurons. J Neurophysiol 88:1707-1715. Medline

Ungless MA, Whistler JL, Malenka RC, Bonci A (2001) Single cocaine exposure in vivo induces long-term potentiation in dopamine neurons. Nature 411:583-587. CrossRef Medline

Urban MO, Coutinho SV, Gebhart GF (1999) Involvement of excitatory amino acid receptors and nitric oxide in the rostral ventromedial medulla in modulating secondary hyperalgesia produced by mustard oil. Pain 81:45-55. CrossRef Medline

Wall PD, Gutnick M (1974a) Properties of afferent nerve impulses originating from a neuroma. Nature 248:740-743. CrossRef Medline

Wall PD, Gutnick M (1974b) Ongoing activity in peripheral nerves: the physiology and pharmacology of impulses originating from a neuroma. Exp Neurol 43:580-593. CrossRef Medline

Wei F, Li P, Zhuo M (1999) Loss of synaptic depression in mammalian anterior cingulate cortex after amputation. J Neurosci 19:9346-9354. Medline

Wei F, Guo W, Zou S, Ren K, Dubner R (2008) Supraspinal glial-neuronal interactions contribute to descending pain facilitation. J Neurosci 28: 10482-10495. CrossRef Medline

Whiteside GT, Munglani R (2001) Cell death in the superficial dorsal horn in a model of neuropathic pain. J Neurosci Res 64:168-173. CrossRef Medline

Wiberg M, Westman J, Blomqvist A (1987) Somatosensory projection to the mesencephalon: an anatomical study in the monkey. J Comp Neurol 264:92-117. CrossRef Medline

Wu LJ, Toyoda H, Zhao MG, Lee YS, Tang J, Ko SW, Jia YH, Shum FW, Zerbinatti CV, Bu G, Wei F, Xu TL, Muglia LJ, Chen ZF, Auberson YP, Kaang BK, Zhuo M (2005) Upregulation of forebrain NMDA NR2B receptors contributes to behavioral sensitization after inflammation. J Neurosci 25:11107-11116. CrossRef Medline

Xu H, Wu LJ, Wang H, Zhang X, Vadakkan KI, Kim SS, Steenland HW, Zhuo M (2008) Presynaptic and postsynaptic amplifications of neuropathic pain in the anterior cingulate cortex. J Neurosci 28:7445-7453. CrossRef Medline

Zhang L, Hammond DL (2009) Substance P enhances excitatory synaptic transmission on spinally projecting neurons in the rostral ventromedial medulla after inflammatory injury. J Neurophysiol 102:1139-1151. CrossRef Medline

Zucker RS, Regehr WG (2002) Short-term synaptic plasticity. Annu Rev Physiol 64:355-405. CrossRef Medline 